Check for updates

Cite this: RSC Adv., 2019, 9, 23570

Received 6th June 2019

Accepted 19th July 2019

DOI: 10.1039/c9ra04266k

rsc.li/rsc-advances

\title{
Gravure printing for mesoporous film preparation $\uparrow$
}

\author{
Nicole Herzog, ${ }^{a}$ Robert Brilmayer, ${ }^{a}$ Mathias Stanzel, ${ }^{a}$ Anastasia Kalyta, ${ }^{a}$ \\ Dieter Spiehl, (DD ${ }^{\mathrm{b}}$ Edgar Dörsam, (D) ${ }^{\mathrm{b}}$ Christian Hess (D) ${ }^{\mathrm{c}}$ and Annette Andrieu- \\ Brunsen (iD *a
}

\begin{abstract}
This study presents gravure printing as a new strategy for rapid printing of ceramic mesoporous films and highlights its advantages over conventional mesoporous film preparation using evaporation induced selfassembly together with dip-coating. By varying the printing process parameters, the mesoporous coating thicknesses can be adjusted between 20 and $200 \mathrm{~nm}$ while maintaining a very high film homogeneity allowing the printing of ultrathin mesoporous films. Step gradients in film composition are accessible by consecutively printing two different "inks". Thereby, gravure printing is a much faster process than mesoporous single- and multilayer preparation using conventional dip-coating because lower amounts of solution are transferred and dissolution of previously deposited layers is avoided. The effect of printing process parameters on resulting film characteristics as well as the resulting mesoporous film's ionic accessibility is systematically investigated.
\end{abstract}

\section{Introduction}

Printing is a powerful tool for manufacturing thin films and coatings. Mesoporous ceramic coatings or thin films are of special interest because they provide an ordered porous framework able to include a variety of functional molecules, resulting in hybrid materials with organized and specific features such as a large surface area and functionalized mesopore walls. These features enable tuning of material characteristics such as ionic permselectivity or optical properties..$^{1-3}$ Therefore, functional mesoporous materials and coatings play a key role in many technological applications such as nanoscale reaction vessels, sensors, optics, separation, catalysis or lab on chip devices. ${ }^{4-12}$ Commonly, mesoporous ceramic coatings are prepared by Evaporation-Induced Self-Assembly (EISA) and solgel chemistry using a dip- or spin-coating process. ${ }^{13}$ Within this process mesoporous film characteristics, especially the film thickness, can be easily adjusted by varying the solvent or withdrawal speed and by varying the geometry of the solution level within the solution reservoir. ${ }^{14,15}$ Despite this versatility, the fabrication of structured or patterned films as well as the automated fabrication of complex coating architectures or ultrathin films of interest e.g. in electronic applications, is not

${ }^{a}$ Ernst-Berl Institut für Technische und Makromolekulare Chemie, Technische Universität Darmstadt, Alarich-Weiss-Str. 4, D-64287 Darmstadt, Germany. E-mail: andrieu-brunsen@smartmem.tu-darmstadt.de

${ }^{b}$ Institute of Printing Science and Technology, Technische Universität Darmstadt, Magdalenenstr. 2, D-64289 Darmstadt, Germany

${ }^{c}$ Eduard-Zintl-Institut für Anorganische und Physikalische Chemie, Technische Universität Darmstadt, Alarich-Weiss-Str. 8, D-64287 Darmstadt, Germany

$\dagger$ Electronic supplementary information (ESI) available. See DOI: 10.1039/c9ra04266k easily possible and film homogeneity, especially with respect to film thickness, varies significantly within the coating. For example, composition control along the film thickness by dipcoating requires multiple dip-coating steps with intermediate temperature-stabilization, to avoid dissolution of previous layers. Aside from being very time consuming, this procedure affects film homogeneity along the film thickness. In addition, substrate rims induce film inhomogeneities, limiting the fabrication of small patterns, for example those desired in microelectronic devices. As another example ultrathin mesoporous films with film thicknesses down to $10 \mathrm{~nm}$, of interest e.g. in electronic devices, have been recently prepared by wetetching previously deposited films. ${ }^{16}$ Printing such films would be much faster and allow much more precise local control. Interestingly, only a few examples of ink-jet printed, structured mesoporous coatings are reported. A technology allowing the construction of highly defined multiple layer and step gradient coatings with the potential for scale up is still missing. ${ }^{17-19}$ Nevertheless, porous structures with well controlled compositions along the film thickness are of special interest in advanced molecular transport control and porous material compartmentalization, and thus in technologies such as sensors, separation or energy conversion. Consequently, a technology allowing homogeneous large area coatings as well as structured deposition while being scalable to an industrial scale that is fast and allows well defined multilayer generation at the nanoscale is required.

These criteria are fulfilled by printing technologies. With respect to mesoporous materials, printing is mainly based on paste printing usually to fabricate net-like macroscopic architectures of mesoporous silica, mostly intended to be used for cell growth..$^{20,21}$ Thereby ordered mesoporous structures such as 
hexagonally arranged mesopores have been demonstrated. ${ }^{20}$ Only a few studies focus on printing with higher local resolution. For example, Kotz et al. show the possibility to print fused silica 3D structures by using stereolithography. ${ }^{22}$ Instead of a sol used for EISA-based dip-coating, $\mathrm{SiO}_{2}$ particles within a UVcurable polymer are applied. Thereby, the polymer matrix stabilizes the 3D structure upon hardening with UV-light followed by sintering resulting in a silica structure. This approach allows the design of transparent 3D silica structures but does not directly allow printing of ordered mesoporous 3D materials. Other experiments to create a 3D ceramic structure are based on ink-jet printing using a layer-by-layer approach, depositing ceramic suspension micro droplets ejected via nozzles. ${ }^{23-25}$ Additionally, the group of Brinker demonstrated silica nanostructures prepared by micro-pen lithography and ink-jet printing. Printing is performed with functional organosilanes on patterned self-assembly monolayers, which leads to functional, hierarchically organized structures. ${ }^{\mathbf{1 7}}$ Unfortunately, inkjet printing of microdot arrays of mesoporous silica is limited by the homogeneity of the dots. For optimal results this technique is limited to hydrophobic organosilanes as co-condensates. ${ }^{26}$ The hydrophobic organosilanes are required to avoid clogging of the nozzle aperture. ${ }^{27}$

Currently, gravure printing is explored as an alternative fabrication process to be combined with sol-gel chemistry. A recent study published in 2018 demonstrates gravure printing of silica nanoparticles for metal oxide thin film formation. ${ }^{28}$ Gravure printing has not yet been used to generate ordered mesoporous silica coatings. Thereby, gravure printing of mesoporous architectures bares a strong potential for automated thin film production with highly defined composition. As a roll to roll process it allows relatively high manufacturing speed of up to $15 \mathrm{~ms}^{-1}$ at up to $4 \mathrm{~m}$ width. ${ }^{29}$ For example, literature describes gravure printing as a good candidate for thin film production in electronics as it allows high throughput, high control of film characteristics and provides the opportunity to print well-defined multiple layers. ${ }^{30}$ With respect to production of complex mesoporous film architectures, gravure printing bares the potential to generate more homogeneous films in much shorter production time as compared to established EISA using dip- or spin-coating and ink-jet printing. In addition, standardization and automation of the film preparation process as well as complex film architecture fabrication should be relatively easy. Combining structuring by gravure printing with different sol inks and co-condensation approaches, known from conventional sol-gel chemistry, and using subsequent postfunctionalization strategies further supports complex film architecture design. In general, gravure printing allows nanoscale adjustment of film thickness and film homogeneity based on the substrate, ink viscosity, cell volume, printing speed and printing force. Consequently, smart process design is expected to not only allow the deposition of nanometer thick, homogeneous, and structured mesoporous film architecture in an automated fashion but also layer selective functional placement.

Here, we establish gravure printing as a rapid and scalable process to prepare homogeneous mesoporous thin film architectures with nanoscale thickness resolution, including multilayer and thus step gradient design, using layer-selective in situ functionalization exemplified for co-condensation of amine functional groups. The gravure printed mesoporous silica film properties, especially ionic mesopore accessibility, are compared to films prepared via conventional dip-coating based evaporation induced self-assembly. The gravure printing process has been optimized by exploring different curing processes and their influence on functional film properties. Regarding functional film properties mesopore ionic permselectivity and the apparent $\mathrm{p} K_{\mathrm{a}}$ values of silanol groups in the confinement of printed mesopores have been explored.

\section{Results and discussion}

The mesoporous silica film preparation process combining evaporation induced self-assembly (EISA) and gravure printing is schematically shown in Fig. 1 and compared to conventionally used dip-coating. The working principle of the gravure printing process starts with filling the cells of the rotating gravure cylinder in an inking unit. A doctor blade removes excess ink so that a defined amount of ink remains within the cells. The layout of the cells determines the printed layout. After further rotation of the cylinder, the cells come into contact with the substrate and most of the ink is transferred onto it. On the substrate, these transferred dots of ink start to merge into a homogeneous layer and the solvent evaporates. Thereby the influence of process parameters such as the cell volume, printing force, withdrawal speed and co-condensate solution composition are systematically controlled and the effect on film characteristics such as film thickness, porosity, and morphology is investigated. In general, gravure printing produces very homogeneous mesoporous silica films on large areas (here $6 \times 20 \mathrm{~cm}^{2}$ ) in an automated fashion. Micrometerscale patches are accessible printing individual spots (Fig. S1b†).

\section{Gravure printed versus dip-coated mesoporous film characterization}

Structural characterization by transmission electron microscopy (TEM) reveals similar mesoporous structures with pores 6$8 \mathrm{~nm}$ in diameter (Fig. 2a and b) for dip-coated and gravure printed mesoporous films. Furthermore, SEM images (ESI Fig. S2 $\dagger$ ) do not show any microscale cracks or structural defects. Gravure printed films appear to be very homogeneous microscopically as well as macroscopically as deduced from very homogeneous optical interference colors (Fig. 2d). Notably, substrate rim effects resulting in thicker films close to the substrate rims are absent when using gravure printing, as observed in electron microscopy and based on the reflected interference color visible for mesoporous films printed onto silicon wafer substrates (Fig. 2e and f). This makes gravure printing a versatile technique to print homogeneous microscopically small area mesoporous film architectures. In contrast to dip-coating, gravure printing easily allows for film thickness and film composition patterns and gradients by adjusting 


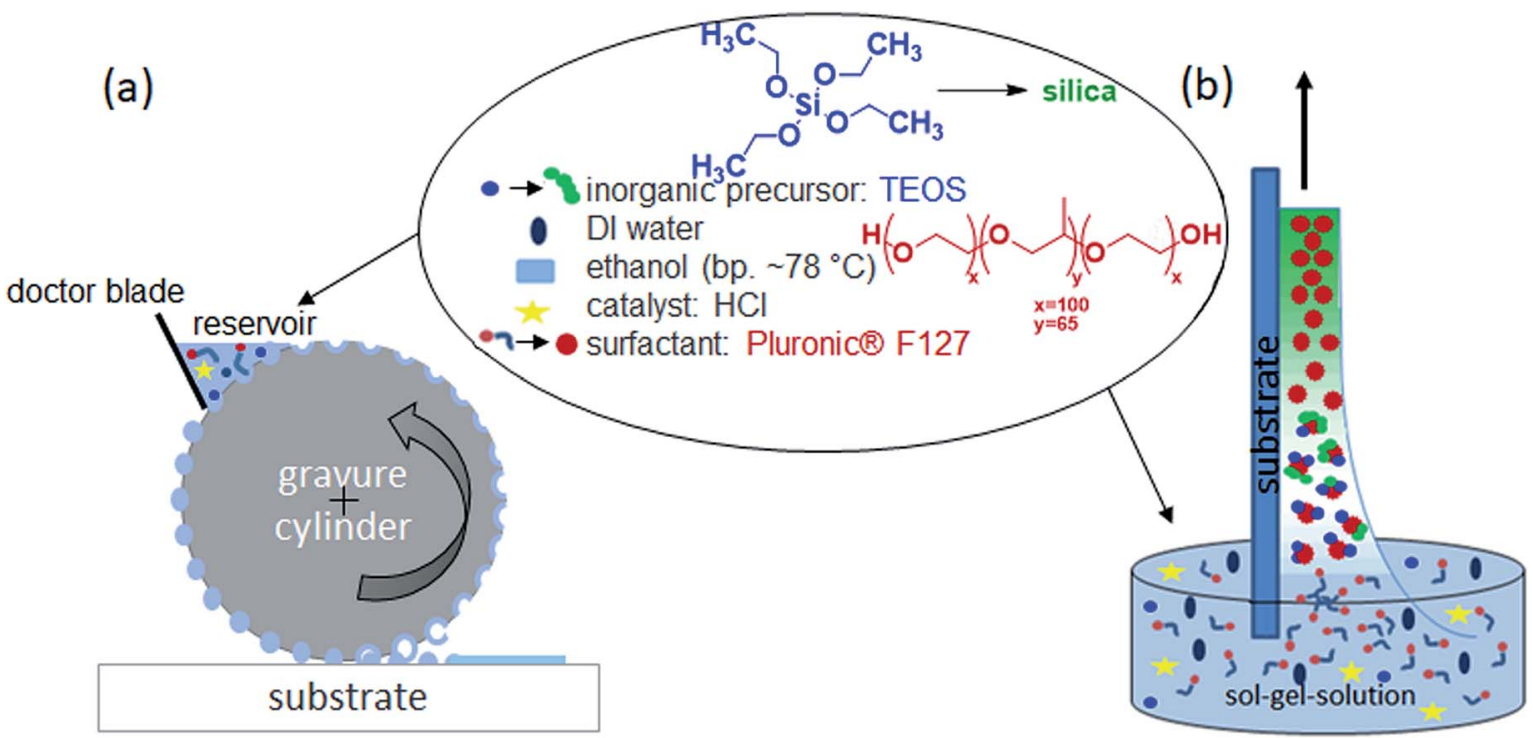

Fig. 1 Comparison of the two mesoporous film preparation strategies, evaporation-induced self-assembly (EISA) by dip-coating or gravure printing. (a) Gravure printing using a metal cylinder transferring the "ink" (sol-gel-solution) to the substrate. The ink is filled out of a reservoir into the cells of the gravure cylinder and directly transferred to the substrate. Excess ink is scraped off by a doctor blade. The cells are not completely emptied, as it comes to a film splitting. The settled fluid spots on the substrate extend to a surface at appropriate ratios of the surface tension of fluid and substrate. The arrangement of the cells specifies the layout to be printed film. The layout repeats after one cylinder revolution. (b) Conventional dip-coating process based on withdrawing a substrate with a defined speed from the sol-gel-solution. The film thickness and quality mainly depends on the used withdrawal speed, solution viscosity and substrate wetting.
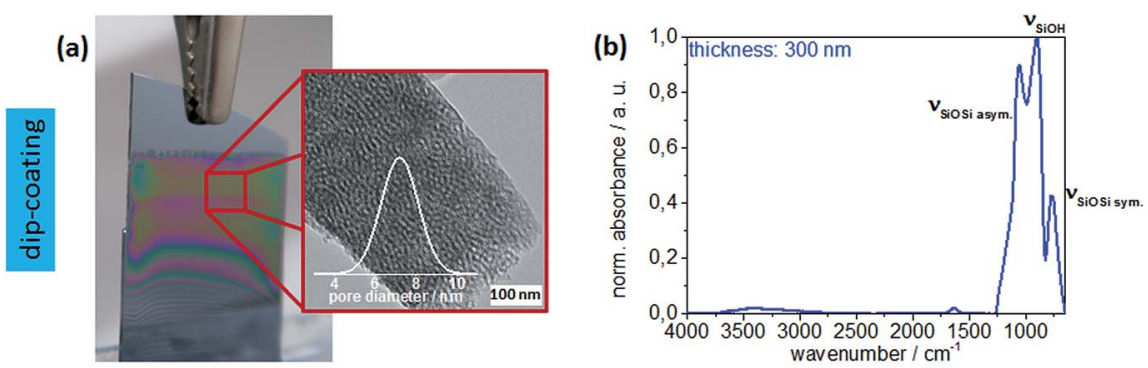

(c)
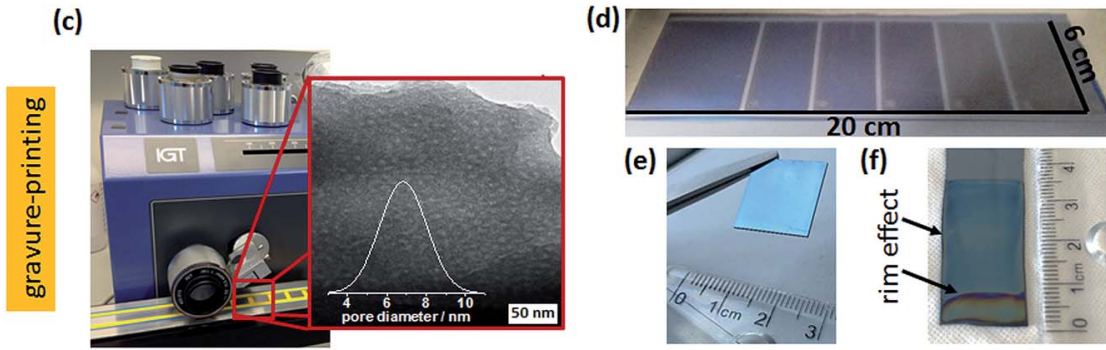

(e)

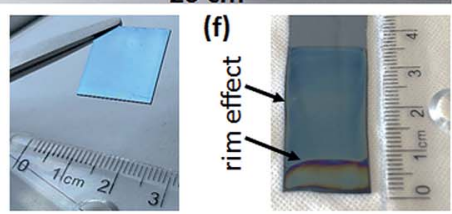

Fig. 2 Comparison of dip-coating ( $a, b$ and $f$ ) and gravure printing ( $c-e)$ as a mesoporous thin film preparation process. (a) Photograph of the dip-coating process as well as TEM image of a mesoporous silica film prepared by dip-coating with a withdrawal speed of 2 mm $\mathrm{s}^{-1}$ and template calcination at $350{ }^{\circ} \mathrm{C}$ showing a statistic pore distribution $(7.2 \pm 0.8 \mathrm{~nm}$ ). (b) Infrared spectra of the mesoporous film after template calcination at $350{ }^{\circ} \mathrm{C}$ measured directly on a glass substrate. (c) Photograph of gravure printed mesoporous silica films and a TEM image of mesoporous silica prepared by gravure printing and calcination at $350^{\circ} \mathrm{C}$ using a cylinder with a cell volume of $8.5 \mathrm{~mL} \mathrm{~m}{ }^{-2}$ with a statistic pore distribution $(6.8 \pm 1.2 \mathrm{~nm})$. (d) Photograph showing the homogeneity of gravure printed mesoporous silica films with different cylinder cell volume field $\left(9.19 \mathrm{~mL} \mathrm{~m}^{-2}, 8.3 \mathrm{~mL} \mathrm{~m}^{-2}, 5.98 \mathrm{~mL} \mathrm{~m}^{-2}, 4.71 \mathrm{~mL} \mathrm{~m}^{-2}, 2.72 \mathrm{~mL} \mathrm{~m}^{-2}\right.$ and $1.67 \mathrm{~mL} \mathrm{~m}^{-2}$ from left to right). By using gravure printing, it is possible to print $\mathrm{mm}$-scale patterns. Substrate size is demonstrated with $6 \mathrm{~cm} \times 20 \mathrm{~cm}$. The different film thickness is visible by the different interference colors. (e) Image of a printed homogeneous mesoporous silica film prepared with a cell volume of $8.5 \mathrm{~mL} \mathrm{~m} \mathrm{~m}^{-2}$. (f) Image of a dip-coated mesoporous silica film prepared with $2 \mathrm{~mm} \mathrm{~s}^{-1}$ withdrawal speed. Inhomogeneity's because of edge effects are indicated by the black arrow and are visible by a colour change at the end of the substrate indicating a different film thickness originating from drop formation during dip-coating (rim effects). 
gravure cylinder cell volume and sol composition (ink), respectively. Without special optimization, our experiments allow resolution down to $10-20 \mathrm{~nm}$ for film thickness while maintaining film homogeneity (Fig. 3) allowing to homogeneously print ultrathin mesoporous films. In accordance with literature, film thicknesses between $60 \mathrm{~nm}$ and $400 \mathrm{~nm}$ are achieved by dip-coating upon varying the withdrawal speed between 0.05 and $30 \mathrm{~mm} \mathrm{~s}^{-1}$ as shown in Fig. 2b. ${ }^{31}$ In gravure printing, the film thicknesses and homogeneity is mainly determined by the cell volume of the grounded cylinders (we used a range from 1.6 to $24 \mathrm{~mL} \mathrm{~cm}^{-2}$ ) resulting in film thickness variation between $20-240 \mathrm{~nm}$ (Fig. 3b) for a contact force of $500 \mathrm{~N}$. In addition, film thickness can be tuned by varying the contact force between gravure cylinder and substrate. Increasing contact force from $500 \mathrm{~N}$ to $700 \mathrm{~N}$ leads to increasing film thickness of 10-20 nm (ESI, Fig. S3†). Consequently, gravure printing yields thinner homogeneous films compared to dip-coating. Porosity (pore volume) of $40-45$ vol\% as calculated from ellipsometry data (refractive index) using Brüggemann effective medium approximation (please refer to the ESI, Tables $\mathrm{S} 1-\mathrm{S} 3 \dagger$ ) is detected for dip-coated as well as gravure printed films. High refractive indices resulting in low porosities of below $20 \mathrm{vol} \%$ are observed only when very small cell volumes of less than $1.67 \mathrm{~mL} \mathrm{~cm}^{-2}$ are used. This can be attributed to insufficient ink transfer resulting in inhomogeneous film
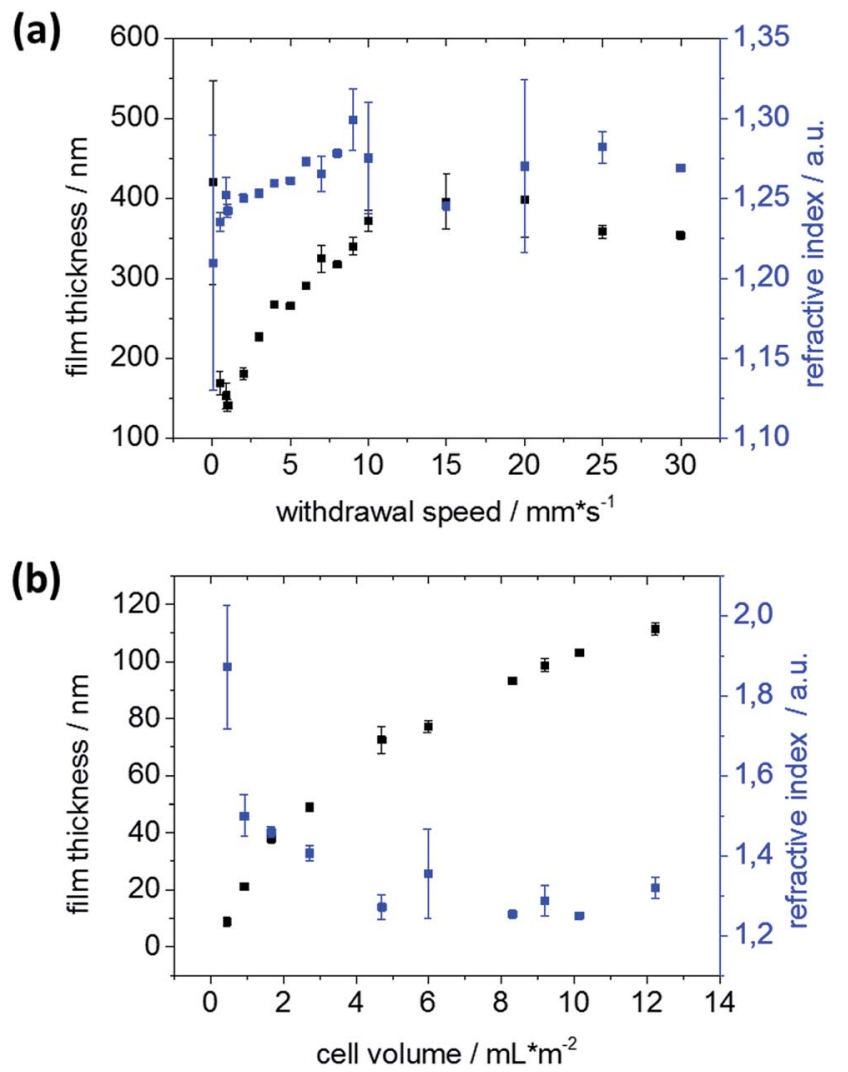

Fig. 3 (a) Film thickness (black) and refractive index (blue) determined by ellipsometry in dependence of the dip-coating withdrawal speed. (b) Film thickness (black) and refractive index (blue) determined by ellipsometry in dependence of the cell volume of the used gravure printing cylinder. formation (ESI, Fig. S1 $\dagger$ ), which is supported by SEM and microscopy results. Using a critical cell volume (above $2 \mathrm{~mL}$ $\mathrm{cm}^{-2}$ ) seems to be crucial for obtaining homogeneous mesoporous silica films by gravure printing with a comparable pore volume to dip-coated mesoporous silica films.

Changing the ink composition can introduce functional groups into the mesopore wall (co-condensation) and produce films with varying pore diameters. Here, we demonstrate pore diameters of about $16 \mathrm{~nm}$ instead of about $8 \mathrm{~nm}$. These films show higher film thickness under identical gravure printing or dip-coating conditions and the calculated pore volume is slightly larger reaching up to 70 vol\% (ESI, Tables S4 and S5 $\dagger$ ). Interestingly, film thickness variation for these films is more sensitive to withdrawal speed and cylinder volume (ESI, Fig. S2 $\dagger$ ) allowing a thickness variation range of $750 \mathrm{~nm}$ between film thickness of 250-1000 nm.

Functional integrity is characterized by using ATR-IR of $350{ }^{\circ} \mathrm{C}$ calcinated mesoporous silica films deposited on glass substrates. Three different silica stretching vibrational bands are observed (Fig. 2b): ${ }^{32}$ the asymmetric stretching vibration of bridged $\mathrm{Si}-\mathrm{O}-\mathrm{Si}$ at $1260-1000 \mathrm{~cm}^{-1}$ and the symmetric stretching vibration of $\mathrm{Si}-\mathrm{O}-\mathrm{Si}$ ring structure at around $800 \mathrm{~cm}^{-1}$, both originating from the silica network $\mathrm{Si}-\mathrm{O}-\mathrm{Si}$ as well as the stretching vibrational band of free silanol ( $\mathrm{Si}-\mathrm{OH})$ groups in the range of $900-980 \mathrm{~cm}^{-1}$. Based on these ATR-IR results no significant difference within the chemical structures, such as degree of silica condensation, can be observed for mesoporous silica films prepared under different process conditions or location on the supporting substrate (compare as well Fig. S4†).

\section{Gravure printed mesoporous film performance}

With respect to technological applications, such as separation, sensing, or catalysis, performance-limiting mesoporous film characteristics are mesopore accessibility and ionic permselectivity. Mesoporous silica ionic permselectivity and mesoporous silica film ionic uptake capability is mainly determined by structural characteristics such as pore size and porosity, together with pore wall functionalisation depending interface characteristics such as charge but might as well be affected by mesoporous film thickness. Walcarius and co-workers for example demonstrate an increasing peak current in cyclic voltammetry, representing, according to Nernst equation, an increasing molecule concentration, with increasing number of mesoporous silica layers produced by dip-coating. ${ }^{33}$ As gravure printing allows very precise adjustment of homogeneous mesoporous layer thickness the correlation of film thickness and ionic permselectivity is shown in Fig. 4 as detected by the maximum peak current density deduced from cyclic voltammetry. Ionic mesopore accessibility of gravure printed and dipcoated mesoporous silica thin films with increasing film thickness using anionic and cationic probe molecules $\left[\mathrm{Fe}\left(\mathrm{CN}_{6}\right)\right]^{3-/ 4-}$ and $\left[\mathrm{Ru}\left(\mathrm{NH}_{3}\right)_{6}\right]^{2+/ 3+}$ at acidic and basic $\mathrm{pH}$ are compared. Thereby film stability has to be considered as recently demonstrated by Alberti et al. ${ }^{34}$ Within the discussed experiments, cycling time has always been kept below 6 

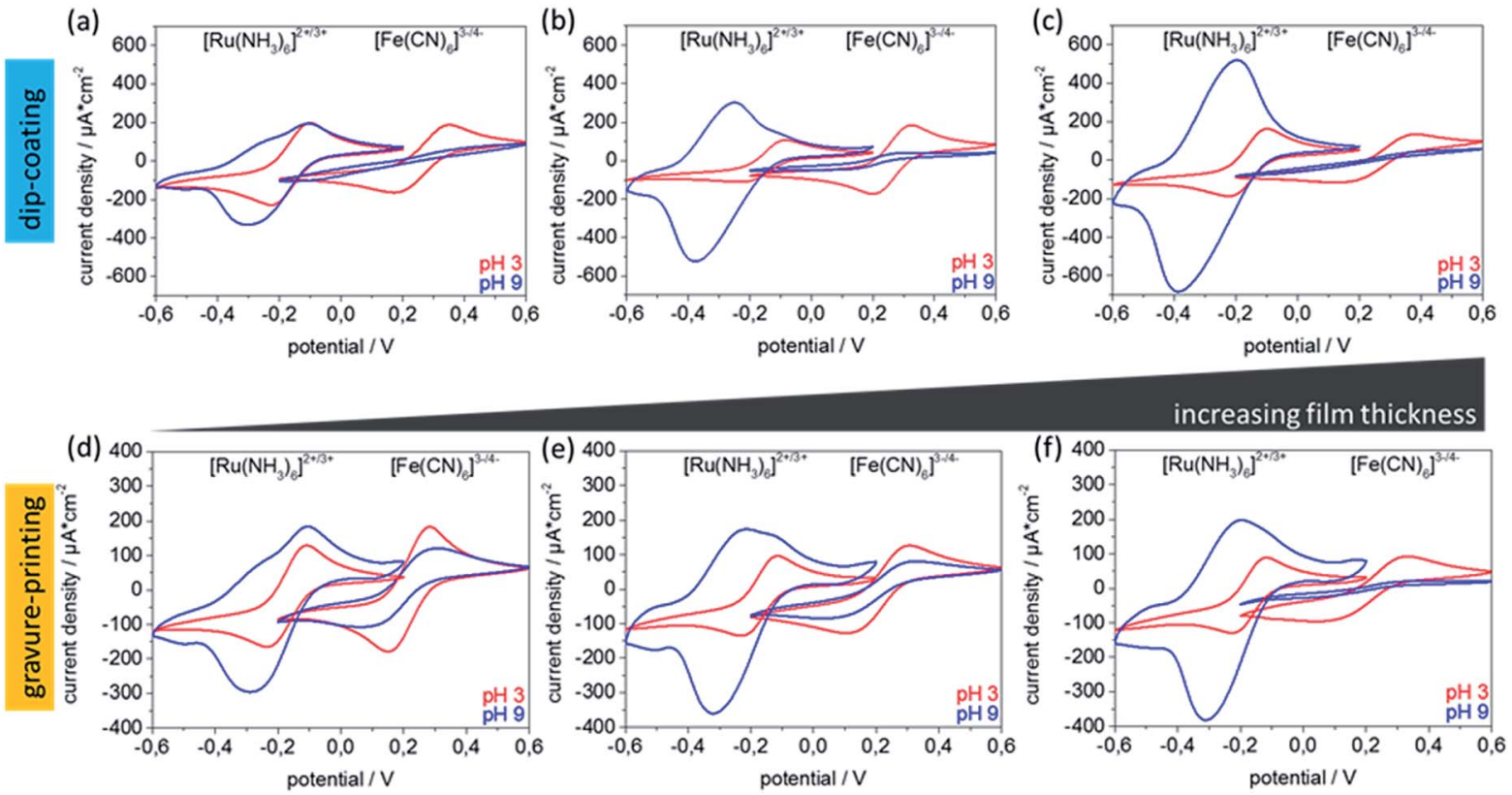

Fig. 4 Cyclic voltammograms of mesoporous silica thin films using $\left[\mathrm{Ru}\left(\mathrm{NH}_{3}\right)_{6}\right]^{2+/ 3+}(-0.6$ to $+0.2 \mathrm{~V})$ and $\left[\mathrm{Fe}(\mathrm{CN})_{6}\right]^{3-/ 4-}(-0.2$ to $+0.6 \mathrm{~V})$ as an ionic redox probes at pH 3 (red) and 9 (blue). The dip-coated mesoporous silica films are prepared with different withdrawal speeds (a) $0.5 \mathrm{~mm}$ $\mathrm{s}^{-1}$ (b) $2 \mathrm{~mm} \mathrm{~s}^{-1}$ and (c) $10 \mathrm{~mm} \mathrm{~s}^{-1}$ resulting in film thicknesses of (a) $140 \mathrm{~nm}$ (47 vol\% porosity), (b) $180 \mathrm{~nm}$ (44 vol\% porosity), (c) $300 \mathrm{~nm}$ (39 vol\% porosity). Mesoporous silica films prepared by gravure printing are prepared using different cell volumes of (d) $8.5 \mathrm{~mL} \mathrm{~m}^{-2}$ (e) $16.3 \mathrm{~mL} \mathrm{~m} \mathrm{~m}^{-2}$ and (f) $24 \mathrm{~mL} \mathrm{~m}{ }^{-2}$ resulting in film thicknesses of (d) $100 \mathrm{~nm}$ (48 vol\% porosity), (e) $162 \mathrm{~nm}$ (40 vol\% porosity), (f) $250 \mathrm{~nm}$ (48 vol\% porosity).

minutes and a strict data quality control has been applied ensuring stable and reproducible cyclic voltammograms as described in Experimental section and Fig. S13.† At basic pH values (Fig. $4 \mathrm{a}-\mathrm{c}$ blue) the silica mesopore wall is negatively charged due to deprotonated silanol groups. Under these conditions an exclusion of $\left[\mathrm{Fe}\left(\mathrm{CN}_{6}\right)\right]^{3-/ 4-}$ due to overlapping Debye screening layers reflected by zero maximum peak current density $\left(j_{\mathrm{p}}\right)$ as well as a preconcentration of positively charged $\left[\mathrm{Ru}\left(\mathrm{NH}_{3}\right)_{6}\right]^{2+/ 3+}$ in the silica mesopores reflected by increased maximum peak-current densities and peak broadening is expected. At acidic $\mathrm{pH}$, and thus neutral pore wall charge, no ion discrimination in pore accessibility and thus similar $j_{\mathrm{p}}$ is expected. In accordance with this expectation both probe molecules show similar, and thickness independent, maximum peak currents at acidic pH (Fig. 4, red). As well in accordance with expectation, electrostatic exclusion of $\left[\mathrm{Fe}\left(\mathrm{CN}_{6}\right)\right]^{3-/ 4-}$ at basic $\mathrm{pH}$ is observed indicating a defect-free film structure. Except for very thin films with a film thickness of below $100 \mathrm{~nm}$ a thickness dependent peak current reduction is observed (Fig. $4 \mathrm{~d}-\mathrm{f}$ ). Interestingly, the preconcentration of $\left[\mathrm{Ru}\left(\mathrm{NH}_{3}\right)_{6}\right]^{2+/ 3+}$ at basic $\mathrm{pH}$ and the simultaneously observed broadening of the cyclic voltammograms seems to be film thickness and thus preparation process dependent, although no direct correlation can be drawn due to the dependence on multiple parameters especially on the free electrode area which is not directly accessible. Reference measurements of unmodified ITO electrodes are shown in Fig. S5. $\uparrow$ These are not showing any peak broadening or preconcentration at basic or acidic pH values. In addition, the ATR-IR spectra (Fig. S4†) do not show differences in the Si-O-
Si to $\mathrm{Si}-\mathrm{OH}$ ratio in dependence of film thickness or preparation process, and ellipsometry indicates comparable pore volumes for all investigated films. Together, this indicates that the variation of $\mathrm{Si}-\mathrm{O}-\mathrm{Si}_{\text {asym./sym. }}$ to $\mathrm{Si}-\mathrm{OH}$ band intensity with varying cylinder volume is probably caused by the mesoporous film thickness but not by a difference in $\mathrm{Si}-\mathrm{OH}$ concentration and thus charge density at the mesopore wall. In addition, data evaluation using Randles-Sevcik's equation (Fig. S6†) indicates that non-diffusional transport becomes significant for mesoporous films thicker than $250 \mathrm{~nm}$ for basic $\mathrm{pH}$ values and positively charged probe molecule and thus with existing attractive electrostatic interaction between pore wall and diffusing ions. This is reflected by a non-linear correlation of peak currents to the square root of scan rates. All these results indicate good accessibility and a comparable behavior for gravure printed to dip-coated mesoporous silica films.

\section{Gravure printing of complex mesoporous film architectures}

Besides the opportunity of printing different inks and thus creating gradient architectures, an advantage of mesoporous film gravure printing is the rapidity of the printing process itself. The very short contact time between supporting substrate and the sol-gel solution leads to fast drying, avoiding penetration of sol into a pre-printed layer and thus facilitating complex but homogeneous, defect-free multilayer fabrication. This allows printing of multiple mesoporous silica layers directly on top of one another without using stabilizing temperature treatments between layer deposition steps, which may negatively affect film homogeneity. Specifically, two-layer 

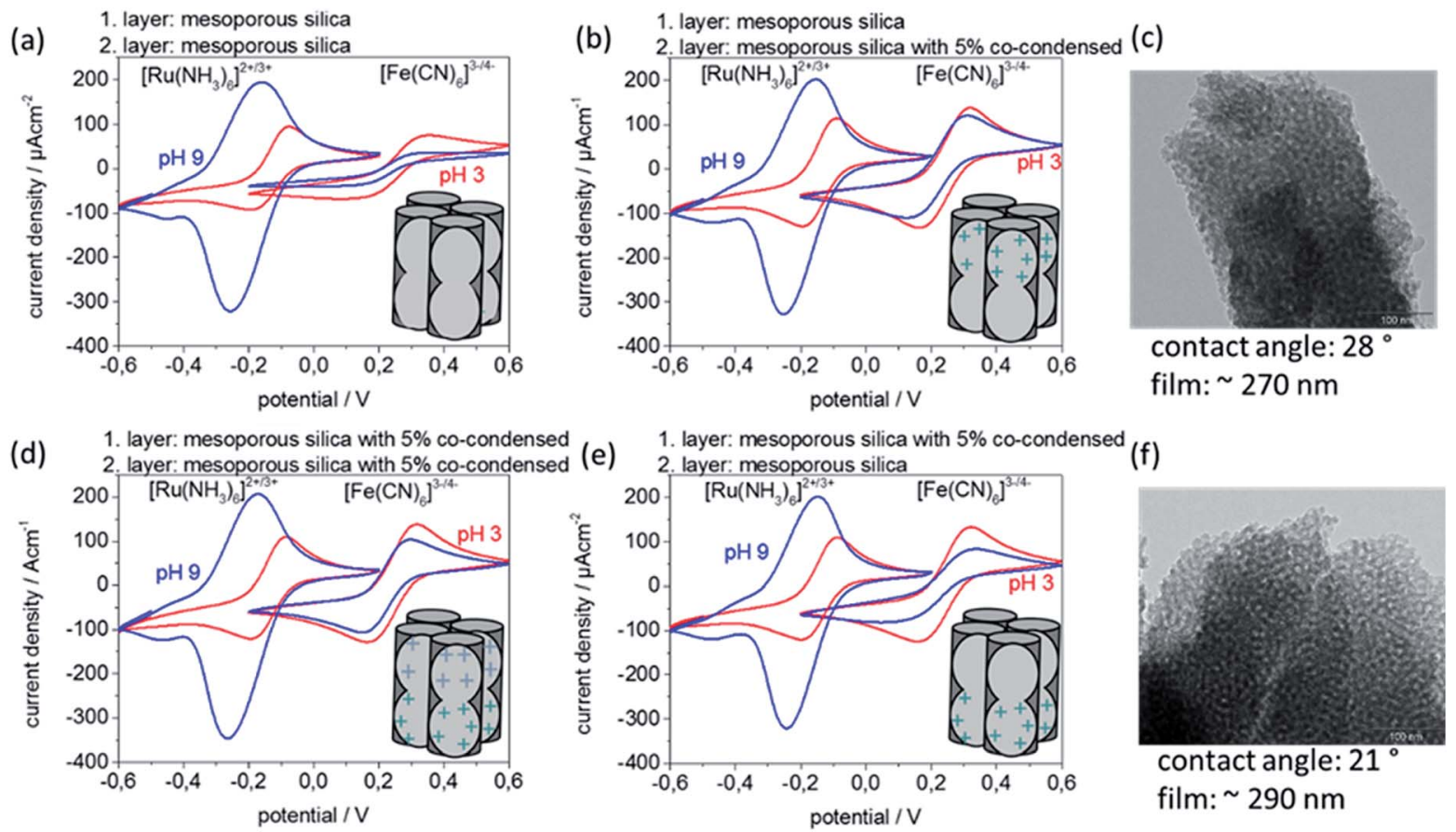

Fig. 5 Cyclic voltammograms of mesoporous silica thin films using $\left[\mathrm{Ru}\left(\mathrm{NH}_{3}\right)_{6}\right]^{2+/ 3+}$ and $\left[\mathrm{Fe}(\mathrm{CN})_{6}\right]^{3-/ 4-}$ as ionic redox probes at $\mathrm{pH} 3(\mathrm{red})$ and 9 (blue). Mesoporous silica films prepared by gravure printing are prepared using the cell volumes $8.5 \mathrm{~mL} \mathrm{~m}^{-2}$ resulting in film thicknesses $150 \mathrm{~nm}$ for one layer and $300 \mathrm{~nm}$ for two layers. (a) Two gravure printed layers of unfunctionalized mesoporous silica. (b) Two gravure printed layers consisting of a first mesoporous silica layer and a second mesoporous silica layer containing 5 mol\% co-condensed (bis(2-hydroxyethyl)-3aminopropyl-triethoxysilane) (c) TEM image of a two-layer mesoporous silica film prepared by gravure printing with two different inks corresponding to (b). (d) Two gravure printed layers of 5 mol\% co-condensed mesoporous silica. (e) Two gravure printed layers consisting of a first mesoporous silica layer containing 5 mol\% co-condensed (bis(2-hydroxyethyl)-3-aminopropyl-triethoxysilane) and a second mesoporous silica layer, (f) TEM image of a two-layer mesoporous silica film prepared by gravure printing with two different inks. The first layer consists of mesoporous silica with $5 \mathrm{~mol} \%$ co-condensed (bis(2-hydroxyethyl)-3-aminopropyl-triethoxysilane) and a second layer of unfunctionalized mesoporous silica. The mesoporous films are thermally treated up to $200^{\circ} \mathrm{C}$ and template extracted with acidic ethanol.

gravure printed mesoporous silica films using two different inks resulting in two different functional layers are prepared (Fig. 5). The corresponding characterization concerning porosity, contact angles, temperature treatment dependent ionic permselectivity, and morphology are summarized within the ESI (Fig. S9-S11 and Table S6†). Thereby it must be considered that layer functionalization by co-condensation of organic functional groups limits the maximum applicable temperatures, here to $200{ }^{\circ} \mathrm{C}$. Successful multilayer step gradient preparation is as well supported by XPS measurements (ESI, Fig. S12 and Table S7 $\dagger$ ). XPS results show one nitrogen atom per seven Si-atoms after printing two layers of $5 \mathrm{~mol} \%$ co-condensed mesoporous silica. When printing one layer of $5 \mathrm{~mol} \%$ mesoporous co-condensed silica followed by a second top layer of mesoporous silica only one nitrogen atom per $32 \mathrm{Si}$-atoms is detected by XPS. Printing $5 \mathrm{~mol} \%$ mesoporous co-condensed silica on top of mesoporous silica leads to one nitrogen atom per $17 \mathrm{Si}$-atoms. The reference sample of two printed mesoporous silica layers shows no nitrogen within the XPS. The discussed double layer gravure printed films (Fig. 5) have a film thickness around $280 \mathrm{~nm}$. According to this estimation XPS detects around $10 \mathrm{~nm}$ of the entire film. ${ }^{35}$

In Fig. 5 cyclic voltammetry measurements of double layer gravure printed films consisting of one mesoporous silica layer and one mesoporous silica containing $5 \mathrm{~mol} \%$ of co-condensed (bis(2-hydroxyethyl)-3-aminopropyl-triethoxysilane) are depicted. The cyclic voltammograms for two layer films consisting of two identical layers of mesoporous silica, measured as reference, are comparable to those shown above for one layer with a comparable film thickness (Fig. 5a and 4d) co-condensation of (bis(2-hydroxyethyl)-3-aminopropyl-triethoxysilane) results into inclusion of amino groups with a $\mathrm{p} K_{\mathrm{a}}$ value around 8 inducing a change of the mesopore wall charge. This results in a reduced exclusion of the negatively charged probe molecule $\left[\mathrm{Fe}(\mathrm{CN})_{6}\right]^{3-1}$ ${ }^{4-}$ at $\mathrm{pH} 9$ visible by a detected $j_{\mathrm{p}}$ of $100 \mu \mathrm{A} \mathrm{cm}{ }^{-2}$ instead of 30 $\mu \mathrm{A} \mathrm{cm} \mathrm{cm}^{-2}$ for unmodified mesoporous silica (Fig. 5d). When printing two layers as a step gradient with different functional composition and individual film thicknesses of $140 \mathrm{~nm}$, here mesoporous silica and 5\% co-condensed mesoporous silica (Fig. 5b and c), the top layer which is in contact with the probe molecule solution seems to determine the overall transport characteristics. When the $5 \mathrm{~mol} \%$ co-condensed mesoporous silica film is located on top (Fig. 5b) the observed pore accessibility is very similar to the pure $5 \mathrm{~mol} \%$ co-condensed mesoporous silica layers (Fig. 5d) showing no exclusion of $\left[\mathrm{Fe}(\mathrm{CN})_{6}\right]^{3-/ 4-}$ at $\mathrm{pH}$ 9. But when the unmodified mesoporous silica layer is located on top of a $5 \mathrm{~mol} \%$ co-condensed mesoporous film the exclusion of negatively charged $\left[\mathrm{Fe}(\mathrm{CN})_{6}\right]^{3-14-}$ at pH 9 is again observed (Fig. 5e). 


\section{Experimental section}

\section{Mesoporous silica film preparation}

Mesoporous silica films are synthesized via sol-gel-chemistry using tetraethyl orthosilicate (TEOS) in the presence of the template Pluronic 8 F127. The precursor solutions (1TEOS : 0.0075F127:40EtOH : $10 \mathrm{H}_{2} \mathrm{O}: 0.2 \mathrm{HCl}$ ) resulting in $8 \mathrm{~nm}$ mesopores or (1TEOS : 0.02F127:40EtOH : $\left.34.5 \mathrm{H}_{2} \mathrm{O}: 0.08 \mathrm{HCl}\right)^{36}$ resulting in $16 \mathrm{~nm}$ mesopores or $((1-x)$ TEOS : $x$ (bis(2-hydroxyethyl)-3aminopropyl-triethoxysilane) : $0.0075 \mathrm{~F} 127: 40 \mathrm{EtOH}: 10 \mathrm{H}_{2} \mathrm{O}: 0.2 \mathrm{HCl}$ ) with $x$ being between 0 and $25 \mathrm{~mol} \%$ are stirred for $24 \mathrm{~h}$ at room temperature before being used to produce mesoporous silica films by evaporation induced self-assembly (EISA) ${ }^{13}$ on silicon wafer, glass, or indium tin oxide coated glass substrates at $40-50 \%$ relative humidity and $298 \mathrm{~K}$.

\section{Dip-coating}

The mesoporous silica films are dip-coated using varying withdrawal speeds between 0.1 and $30 \mathrm{~mm} \mathrm{~s}^{-1}$. After deposition the films were kept at $50 \%$ relative humidity for $1 \mathrm{~h}$ followed by a stabilizing thermal treatment and extraction like for films treated to $200{ }^{\circ} \mathrm{C}$. After successful film deposition a stabilizing thermal treatment is carried out in two successive $1 \mathrm{~h}$ steps at 60 and $130{ }^{\circ} \mathrm{C}$. Consecutively, the temperature is increased to $350{ }^{\circ} \mathrm{C}$, or to $200{ }^{\circ} \mathrm{C}$, with a gradient of $1{ }^{\circ} \mathrm{C} \mathrm{min}^{-1}$. This final film stabilization temperature is applied for $2 \mathrm{~h}$. Finally, the films treated up to $350{ }^{\circ} \mathrm{C}$ are rinsed with ethanol and stored under ambient conditions. Template extraction of the films, treated only up to $200{ }^{\circ} \mathrm{C}$, are treated with acidic ethanol $(0.01 \mathrm{M}$ $\mathrm{HCl}$ in abs. ethanol) for 3 days to remove the mesopore template.

\section{Gravure printing}

The mesoporous silica films are gravure printed using a laboratory scale gravure printing machine G1-5 (IGT Testing Systems) with different gravure cylinder cell volumes between 0.2 and $24 \mathrm{~mL} \mathrm{~m}^{-2}$. A printing speed of $0.6 \mathrm{~m} \mathrm{~s}^{-1}$ and a printing force of $700 \mathrm{~N}$ are used. Freshly deposited films are stored at $50 \%$ relative humidity for $1 \mathrm{~h}$. In case of printing two layers the cylinder with $8.5 \mathrm{~mL} \mathrm{~m}^{-2}$ cell volume was used. Between the first and the second layer an aging time of $10 \mathrm{~min}$ is used. After deposition of the second layer films were kept at 50\% relative humidity for $1 \mathrm{~h}$ followed by an identical stabilizing thermal treatment and chemical template extraction used for dip-coated films treated up to $200{ }^{\circ} \mathrm{C}$ : after successful film deposition a stabilizing thermal treatment is carried out in two successive $1 \mathrm{~h}$ steps at 60 and $130{ }^{\circ} \mathrm{C}$. Consecutively, the temperature is increased to $350{ }^{\circ} \mathrm{C}$, or to $200{ }^{\circ} \mathrm{C}$ in case of co-condensed mesoporous silica films, with a gradient of $1{ }^{\circ} \mathrm{C} \mathrm{min}^{-1}$. This final film stabilization temperature is applied for $2 \mathrm{~h}$. Finally, the films treated up to $350{ }^{\circ} \mathrm{C}$ are rinsed with ethanol and stored under ambient conditions. Template extraction of the films with co-condensed organic groups, treated only up to $200{ }^{\circ} \mathrm{C}$, are treated with acidic ethanol ( $0.01 \mathrm{M} \mathrm{HCl}$ in abs. ethanol) for 3 days to remove the mesopore template.

\section{Infrared spectroscopy (IR)}

IR is performed using a Spectrum One (PerkinElmer) instrument in attenuated total reflection mode. The measured spectra are automatically background corrected, measured at glass surface and normalized to the $\mathrm{Si}-\mathrm{OH}$ vibrational band at $912 \mathrm{~cm}^{-1}$.

\section{Ellipsometry}

Film thicknesses and refractive indices are determined on silicon wafer substrates using a Nanofilm EP3 imaging ellipsometer. One zone angle of incidence (AOI) variation measurements are captured between AOIs of 38 and $68^{\circ}$ using a $658 \mathrm{~nm}$ laser. The relative humidity is constantly adjusted to $15 \%$ using a humidity control (ACEflow, Solgelway). The apparent film thickness and refractive indices are calculated from the measured angles $\Psi$ and $\Delta$ using the EP4 analysis software supplied with the instrument. The fitting parameters for the silicon oxide layer thickness on the wafer substrate $\left(d\left(\mathrm{SiO}_{x}\right)=\right.$ $2.8 \mathrm{~nm}$ ) are measured separately. The measured data is fitted with a one-layer box model. The fitting program is allowed to vary film thickness of the mesoporous silica thin films between 100 and $500 \mathrm{~nm}$ and the refractive index between 1.1 and 1.7. All films are measured at three defined positions before and after each functionalization step. Changes in film thickness and refractive index are calculated for each specific position. Error bars result from the changes in $n$ and $d$ at these three different positions. To determine the porosity from refractive indices the Brüggemann effective medium approximation was used as discussed elsewhere..$^{37,38}$

\section{Transmission electron microscopy (TEM)}

TEM measurements are recorded using a FEI CM20 TEM microscope with a maximum resolution of $2.3 \AA$, equipped with a LAB- 6 cathode and a charge coupled device camera (Olympus), using an acceleration voltage of $200 \mathrm{kV}$. Samples are scratched from substrate, dispersed in ethanol and sonicated. Subsequently, the suspension is placed onto a TEM grid.

\section{Scanning electron microscopy (SEM)}

Scanning electron microscopy (SEM) micrographs were acquired using a Philips XL30 FEG scanning electron microscope operated at an acceleration voltage of $30 \mathrm{kV}$. Samples are sputtered prior to analysis with a platinum/palladium layer of $3 \mathrm{~nm}$ using a Sputter Coater $208 \mathrm{HR}$ comprising a thickness controller MTM-20 (both Cressington).

\section{Cyclic voltammetry (CV)}

Quantitative variations of ionic mesopore permselectivity are studied by following the changes of voltammetric peak currents associated with cationic $\left[\mathrm{Ru}\left(\mathrm{NH}_{3}\right)_{6}\right]^{2+/ 3+}$ and anionic $\left[\mathrm{Fe}(\mathrm{CN})_{6}\right]^{3-/ 4-}$ redox probes. Cyclic voltammograms and thus maximum peak currents, are recorded using an Autolab PGSTAT302N (Metrohm). All probe molecule solutions are prepared with a concentration of $1 \mathrm{mM}$ in $100 \mathrm{mM} \mathrm{KCl}$ as supporting electrolyte resulting in a $\mathrm{pH}$ 5-6 solution besides 
measurements shown in ESI (Fig. S7 $\dagger$ ) which are measured in $150 \mathrm{mmol}$ PBS solution as supporting electrolyte. Acidic or basic conditions ( $\mathrm{pH} 3$ and $\mathrm{pH}$ ) are adjusted by adding a drop of a concentrated $\mathrm{HCl}$ or $\mathrm{NaOH}$ solution directly before starting the measurement. Mesoporous silica films are prepared on indium tin oxide (ITO) coated glass substrates being used as working electrode. An Ag/AgCl electrode (BASi RE-6) serves as reference electrode, and a carbon electrode as counter electrode. Various scan rates between 25 and $1000 \mathrm{mV} \mathrm{s}^{-1}$ are measured. The electrode area is $0.21 \mathrm{~cm}^{2}$. Cyclic voltammetry data are strongly quality controlled by measuring the scanrate of $200 \mathrm{mV} \mathrm{s}^{-1}$ at the beginning and at the end of each scanrate variation. Only if both scans are comparable the data are further evaluated. In addition each scanrate is measured three times and the data is only further evaluated if these scans are comparable. Finally, the first pH-value is re-measured for all scanrates after screening all $\mathrm{pH}$-values in between and the data are only further evaluated if the first and the last measurement of one $\mathrm{pH}$ series are comparable. For an example please refer as well to Fig. S13 (ESI $\dagger$ ).

\section{Contact angle}

Macroscopic static contact angle measurements are performed using model TBU90E from company Dataphysics Instruments $\mathrm{GmbH}$ with the Program SCA-Software. The static contact angles are measured using a $1 \mu \mathrm{L} \mathrm{s}^{-1}$ rate with a final DI water drop volume of $2 \mu \mathrm{L}$.

\section{X-ray photoelectron spectroscopy (XPS)}

XP spectra were recorded on a SSX 100 ESCA spectrometer (Surface Science Laboratories Inc.) equipped with a monochromatic $\mathrm{Al} \mathrm{K} \alpha \mathrm{X}$-ray source $(100 \mathrm{~W})$. XPS analysis reveals peaks at around $103 \mathrm{eV}, 154 \mathrm{eV}, 200 \mathrm{eV}, 285 \mathrm{eV}, 400 \mathrm{eV}, 533 \mathrm{eV}$, and $1073 \mathrm{eV}$, which are attributed to Si2p, Si2s, Cl2p, C1s, N1s, O1s, and Na1s photoemissions, respectively. ${ }^{39}$ The observed Si2p, Si2s and O1s peaks are consistent with the presence of silica, whereas the N1s peak originates from the nitrogen in the co-initiator. The presence of small amounts of $\mathrm{K}, \mathrm{Na}$, indium and $\mathrm{Cl}$ may result from indium-thin-oxide coated glass support substrate.

\section{Conclusions}

In summary, this study demonstrates the versatility of gravure printing for preparation of homogeneous, large area and complex architecture mesoporous coatings in comparison to conventionally used dip-coating. The resulting printed mesoporous silica films are more homogeneous and show no substrate rim effects even on very large areas. The fabrication of ultrathin homogeneous films down to a film thickness of $20 \mathrm{~nm}$ is possible and film thickness can be tuned by adjusting process parameters such as the printing cylinder cell depth and the contact force. Fast and homogeneous multilayer fabrication with nanoscale thickness resolution has been demonstrated relying on preventing sol incubation into bottom, pre-printed layers due to the controlled, low solution volume applied to the substrate. Thereby, the achieved film properties, such as high porosity and $\mathrm{pH}$-dependent ionic permselectivity, are comparable to dip-coated films. Using co-condensation and different sol compositions for gravure printing enables the fabrication of homogeneous multi-layer films with nanoscale step gradient in porosity, pore size, or layer functionalization and thus charge density. For such multilayer films the ionic permselectivity is influenced by the condensation degree of the mesoporous silica (due to temperature treatment), film thickness, and in case of double layer films with pore sizes below the Debye screening length and layer thicknesses of about $280 \mathrm{~nm}$, seems to be determined by the second layer which is in contact with the probe molecule solution. Based on the advantages of gravure printing for mesoporous film preparation and its potential for automation and complex film architecture design we expect these results to impact scale up and application potential of mesoporous films.

\section{Conflicts of interest}

There are no conflicts to declare.

\section{Acknowledgements}

The authors acknowledge the Adolf-Messer Stiftung and the DFG grant BR-4806/4-1 for recognition and financial support of this work. The authors thank Karl Kopp for performing XPSmeasurements. We especially thank Ulrike Kunz and Prof. Kleebe from the Material Science Department of the Technische Universität Darmstadt for their support with TEM measurements. Prof. Markus Biesalski for access to interface characterization facilities and the Merck Lab @ TU Darmstadt for access to gravure printing machine and sputter coater. Janine Herzog is acknowledged for calculation of pore size distribution. Robert Brilmayer further acknowledges support in the frame of the LOEWE project iNAPO by the Hessen State Ministry of Higher Education, Research and the Arts. Dieter Spiehl thanks the Merck KGaA for financial support through the Merck Lab @ TU Darmstadt. The German Research Foundation (DFG) funded Collaborative Research Centre 1194 "Interaction between Transport and Wetting Processes", Project "C04, C01" is kindly acknowledged for enabling fruitful discussion. This study represents initial work for an ERC Starting Grant (grant agreement number 803758). We acknowledge support by the German Research Foundation and the Open Access Publishing Fund of Technische Universität Darmstadt.

\section{Notes and references}

1 A. Walcarius, Chem. Soc. Rev., 2013, 42, 4098-4140.

2 P. Innocenzi and L. Malfatti, Chem. Soc. Rev., 2013, 42, 41984216.

3 G. J. Soler-Illia and O. Azzaroni, Chem. Soc. Rev., 2011, 40, 1107-1150.

4 M. E. Davis, Nature, 2002, 417, 813-821.

5 G. M. Whitesides, Small, 2005, 1, 172-179. 
6 C. Burda, X. Chen, R. Narayanan and M. A. El-Sayed, Chem. Rev., 2005, 105, 1025-1102.

7 Y. Piao, A. Burns, J. Kim, U. Wiesner and T. Hyeon, Adv. Funct. Mater., 2008, 18, 3745-3758.

8 D. Grosso, F. Cagnol, G. J. A. A. Soler-Illia, E. L. Crepaldi, H. Amenitsch, A. Brunet Bruneau, A. Bourgeois and C. Sanchez, Adv. Funct. Mater., 2004, 14, 309-322.

9 J. Hwang, N. Shoji, A. Endo and H. Daiguji, Langmuir, 2014, 30, 15550-15559.

10 A. Brunsen, A. Calvo, F. J. Williams, G. J. Soler-Illia and O. Azzaroni, Langmuir, 2011, 27, 4328-4333.

11 A. Brunsen, J. Cui, M. Ceolin, A. del Campo, G. J. Soler-Illia and O. Azzaroni, Chem. Commun., 2012, 48, 1422-1424.

12 C. Sanchez, P. Belleville, M. Popall and L. Nicole, Chem. Soc. Rev., 2011, 40, 696-753.

13 C. J. Brinker, Y. Lu, A. Sellinger and H. Fan, Adv. Mater., 1999, 11, 579-585.

14 M. Faustini, C. Boissière, L. Nicole and D. Grosso, Chem. Mater., 2013, 26, 709-723.

15 E. Bindini, G. Naudin, M. Faustini, D. Grosso and C. Boissière, J. Phys. Chem. C, 2017, 121, 14572-14580.

16 M. Kobayashi, K. Susuki, T. Otani, S. Enomoto, H. Otsuji, Y. Kuroda, H. Wada, A. Shimojima, T. Homma and K. Kuroda, Nanoscale, 2017, 9, 8321-8329.

17 H. Fan, Y. Lu, A. Stump, S. T. Reed, T. Baer, R. Schunk, V. Perez-Luna, G. P. López and C. J. Brinker, Nature, 2000, 405, 56-60.

18 T. Homola, M. Shekargoftar, P. Dzik, R. Krumpolec, Z. Ďurašová, M. Veselý and M. Černák, Flexible Printed Electron., 2017, 2, 035010.

19 T. T. Baby, M. Rommel, F. von Seggern, P. Friederich, C. Reitz, S. Dehm, C. Kubel, W. Wenzel, H. Hahn and S. Dasgupta, Adv. Mater., 2017, 29, 1603858.

20 F. Putz, S. Scherer, M. Ober, R. Morak, O. Paris and N. Hüsing, Adv. Mater. Technol., 2018, 1800060, DOI: 10.1002/admt.201800060.

21 E. B. Duoss, M. Twardowski and J. A. Lewis, Adv. Mater., 2007, 19, 3485-3489.

22 F. Kotz, K. Arnold, W. Bauer, D. Schild, N. Keller, K. Sachsenheimer, T. M. Nargang, C. Richter, D. Helmer and B. E. Rapp, Nature, 2017, 544, 337-339.
23 G. Senlis, M. Dubarry, M. Lejeune and T. Chartier, Ferroelectrics, 2002, 273, 279-284.

24 R. Noguera, C. Dossou-Yovo, M. Lejeune and T. Chartier, J. Eur. Ceram. Soc., 2005, 126, 133-137.

25 R. Noguera, M. Lejeune and T. Chartier, J. Eur. Ceram. Soc., 2005, 25, 2055-2059.

26 M. Mougenot, M. Lejeune, J. F. Baumard, C. Boissiere, F. Ribot, D. Grosso, C. Sanchez and R. Noguera, J. Am. Ceram. Soc., 2006, 89, 1876-1882.

27 B. Fousseret, M. Mougenot, F. Rossignol, J.-F. o. Baumard, B. Soulestin, C. d. Boissière, F. o. Ribot, D. Jalabert, C. Carrion, C. m. Sanchez and M. Lejeune, Chem. Mater., 2010, 22, 3875-3883.

28 G. Sico, M. Montanino, C. T. Prontera, A. De Girolamo Del Mauro and C. Minarini, Ceram. Int., 2018, 44, 19526-19534. 29 R. Wilken, I. Pollex, S. Stahl, E. Dörsam, R. Klein and M. Miletić, Handbook of Paper and Board, Wiley-VCH Verlag GmbH \& Co. KGaA, Weinheim, Germany, 2nd edn, 2013.

30 D. Spiehl, M. Haming, H. M. Sauer, K. Bonrad and E. Dorsam, IEEE Trans. Electron Devices, 2015, 62, 2871-2877.

31 M. Faustini, D. R. Ceratti, B. Louis, M. Boudot, P. A. Albouy, C. Boissiere and D. Grosso, ACS Appl. Mater. Interfaces, 2014, 6, 17102-17110.

32 R. F. S. Lenza and M. L. Vasconcelos, Mater. Res., 2001, 4, 189-194.

33 G. Giordano, N. Vilà, E. Aubert, J. Ghanbaja and A. Walcarius, Electrochim. Acta, 2017, 237, 227-236.

34 S. Alberti, P. Y. Steinberg, G. Giménez, H. Amenitsch, G. Ybarra, O. Azzaroni, P. C. Angelomé and G. J. A. A. Soler-Illia, Langmuir, 2019, 35, 6279-6287.

35 A. Calvo, P. C. Angelomé, C. Sanchez, D. A. Scherlis, F. J. Williams and G. J. A. A. Soler-Illia, Chem. Mater., 2008, 20, 4661-4668.

36 D. R. Dunphy, P. H. Sheth, F. L. Garcia and C. J. Brinker, Chem. Mater., 2015, 27, 75-84.

37 C. Boissiere, D. Grosso, S. Lepoutre, L. Nicole, A. Brunet Bruneau and C. Sanchez, Langmuir, 2005, 21, 12362-12371.

38 J. E. Spanier and I. P. Herman, Phys. Rev. B: Condens. Matter Mater. Phys., 2000, 61, 10437-10450.

39 J. F. Moulder, W. F. Stickle, P. E. Sobol and K. D. Bomben, Handbook of X-ray Photoelectron Spectroscopy, Physical Electronics Inc., USA, 1995. 